\title{
CULTURAL HERITAGE IN SMART CITY ENVIRONMENTS: THE UPDATE
}

\author{
M. Angelidou ${ }^{\mathrm{a}}$, E. Stylianidis ${ }^{\mathrm{a}}$ \\ ${ }^{a}$ School of Spatial Planning and Development, Faculty of Engineering, Aristotle University, Thessaloniki, 54124, Greece \\ mangel@auth.gr; sstyl@auth.gr
}

KEY WORDS: Smart city; urban development; urban innovation; touristic development; cultural heritage management

\begin{abstract}
:
In 2017 we published a seminal research study in the International Archives of the Photogrammetry, Remote Sensing \& Spatial Information Sciences about how smart city tools, solutions and applications underpinned historical and cultural heritage of cities at that time (Angelidou et al. 2017). We now return to investigate the progress that has been made during the past three years, and specifically whether the weak substantiation of cultural heritage in smart city strategies that we observed in 2017 has been improved. The newest literature suggests that smart cities should capitalize on local strengths and give prominence to local culture and traditions and provides a handful of solutions to this end. However, a more thorough examination of what has been actually implemented reveals a (still) rather immature approach. The smart city cases that were selected for the purposes of this research include Tarragona (Spain), Budapest (Hungary) and Karlsruhe (Germany). For each one we collected information regarding the overarching structure of the initiative, the positioning of cultural heritage and the inclusion of heritage-related smart city applications. We then performed a comparative analysis based on a simplified version of the Digital Strategy Canvas. Our findings suggest that a rich cultural heritage and a broader strategic focus on touristic branding and promotion are key ingredients of smart city development in this domain; this is a commonality of all the investigated cities. Moreover, three different strategy architectures emerge, representing the different interplays among the smart city, cultural heritage and sustainable urban development. We conclude that a new generation of smart city initiatives is emerging, in which cultural heritage is of increasing importance. This generation tends to associate cultural heritage with social and cultural values, liveability and sustainable urban development.
\end{abstract}

\section{INTRODUCTION}

Today smart cities represent a broadly established development paradigm all over the world. Only in Europe, one of the world's cradles of culture and civilization, it is estimated that over 240 medium and large sized cities pursue smart city objectives and implement smart city programmes (Euractiv 2017). The exact number of how many of those cities also host major historic urban landscapes is not known, but a look at the unique concentration of such sites in Europe (UNESCO 2019) provides evidence that most of those cities that are pursuing a smart city trajectory might also possess significant cultural heritage assets (Figure 1).

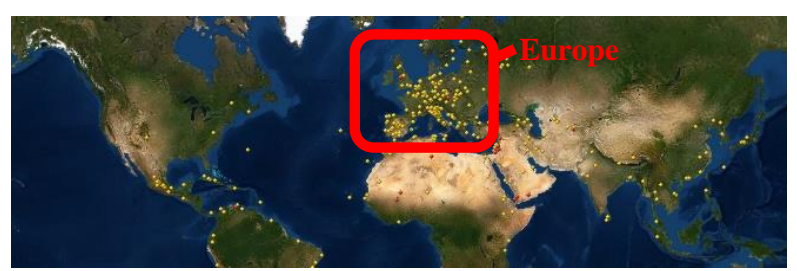

Figure 1. Historic urban landscapes world-wide and their concentration in Europe (UNESCO 2019).

Three years ago we implemented and published a seminal and broadly referenced research study investigating how smart city tools, solutions and applications underpinned historical and cultural heritage of cities at that time (Angelidou et al. 2017). The findings of that study suggested that despite the existence of different integration routes of local cultural heritage in smart city strategies, either as tourism asset, component of quality of life, or substantial element of public services for citizens and visitors, cultural heritage as an objective was only fragmentarily addressed within smart city strategies. This represented a missed opportunity to use cultural heritage as a reference point for local innovation; to cultivate vibrant and intelligent communities around cultural heritage; to attract investment in and for cultural heritage; and overall, to improve liveability and socio-economic prosperity by successfully incorporating cultural heritage as a key asset of the smart city.

In the present paper we return to update and expand the study of 2017, examining whether progress has been made to address the weak substantiation of cultural heritage in smart city strategies, and if yes, towards which direction. To this end, we use primarily literature sources that have been published during the past three years. In section 2 we provide the newest literature, in section 3 we provide the methodology of our research, in section 4 the results and in section 5 the conclusions.

\section{CULTURAL HERITAGE IN SMART CITY ENVIRONMENTS - THE NEWEST LITERATURE}

Broadly speaking, smart cities represent an innovation-driven development paradigm that gained increasing attention during the past decade (Mora, Reid, and Angelidou 2019). Smart cities utilize both human capabilities and technological means to improve the innovation capacity of individuals, institutions and services in urbanized environments, where the need to drive sustainable and inclusive development is particularly important (Mora, Reid, and Angelidou 2019, De Falco, Angelidou, and Addie 2018). To this end, smart cities can and should capitalize on local assets and strengths and give prominence to local culture and traditions, while responding to local challenges (Angelidou 2017, Angelidou and Mora 2019) and opening the way for sustainable development (Dixon 2018). 
Nevertheless, smart cities -still today- represent a concept that is under evolvement, largely focusing on the 'modernist' aspects of development, failing to address the cultural and historical aspects of the city and to assign new meanings to people and places (Allam and Newman 2018). In general lines, a static approach to heritage and culture is adopted in contemporary innovation strategies, neglecting the potential of advanced Information and Communication Technology (ICT) tools to render citizens and visitors as equal co-creators and co-consumers of cultural experiences (Trinchini and Spyriadis 2019). Moreover, most smart city initiatives do not take advantage of the multiple synergies that could emerge from the integration of different urban development objectives (Cowley, Joss, and Dayot 2018), for example sound and sustainable transport management with cultural promotion; a better mapping, representation and information of cultural heritage sites for better informed urban planning and attraction of tourism investment; or the adaptation to climate change and rising sea levels in major historical sites. The above are accompanies by a limited understanding of the impacts of smart city technologies on culture and cultural industries (Trinchini and Spyriadis 2019).

The reality of smart city projects points to analogous shortcomings. The European Innovation Partnership (EIP) on Smart Cities and Communities (SCC) is developing an initiative to promote 'Governance for Cultural Heritage' in the Netherlands (EIP-SCC 2016) which, however, appears to be inactive at present. The smart city initiative of Vienna envisions that innovative applications will be developed across a range of domains, including culture and leisure (Stadt Wien 2019). In the smart city of Stockholm all urban assets, including heritage assets, are seen as potentially conducive to environmental, financial and social sustainability (Stokholms Stad 2017). In the smart city of Heraklion a range of interactive applications enable physical and digital browsing across heritage and other cultural assets (Municpality of Heraklion 2019). Similar intentions to promote cultural heritage within smart city initiatives can be found the cities of Graz (Austria), Budapest (Hungary) and Tarragona (Spain) (UNESCO World Heritage Centre 2019). Yet despite these programmatic intentions, a thorough search for specific initiatives in the heritage and culture domains within the above smart city strategies reveals the existence of scarce -if any- dedicated objectives, processes and applications to establish sound cultural heritage management and promotion as a key ingredient of the smart city.

From the side of cultural heritage management, another range of shortcomings is identified. Academic publications, to begin with, mostly present standalone smart city applications that promote cultural heritage and creative attractions (Trinchini and Spyriadis 2019). For example, Piccialli and Chianese (2018) edited a special issue devoted to the use of specific technologies such as the Internet of Things (IoT) to develop immersive and pervasive solutions in cultural environments. Monteiro et al. (2018) present the tools and services that comprise the Smart Heritage City (SHCity) project platform, purposed to improve the integrated management of historic urban areas. Koukopoulos, Koukopoulos, and Jung (2018) present an ICT system based on crowdsourcing, useful for real-time cultural event management. Valentini et al. (2018) provide an extensive review of cutting-edge technologies and sensors on portable devices, which can be used to monitor and control the physical environment of cultural heritage sites, as well as diagnose and restore art works. Altogether, recent research and practice focus on smart technological applications that mostly use sensors and other hardware and software for various purposes, and specifically i) to enhance visitors' experience of heritage sites, ii) to promote acquaintance with a specific cultural heritage asset, iii) to safeguard and preserve cultural heritage and iv) to better manage conditions and utilities (temperature, humidity, energy, lighting) in heritage sites.

The positive development, compared to our research from 2017 (Angelidou et al. 2017), is that a first set of academic publications that put forward a holistic integration of cultural heritage as a preservable, exploitable, and multifaceted asset able to promote urban regeneration and urban innovation in a smart city framework has made its appearance. Allam and Newman (2018) proposed the first integrated smart city framework that clearly includes culture as one of the three constituting dimensions of the smart city (Figure 2), pointing also that new stakeholders collaboration models and demonstrators need to be developed. Kourtit (2019) argues about the necessity of the development of intelligent, datadriven cultural policies for knowledge-driven development in smart cities. Koukopoulos (2019) developed a methodology for the integrated development, management and evaluation of intelligent digital environments that support culture and cultural heritage. In all cases, integrated approaches between the historical and contemporary characteristics of the physical environment, any digital components and tools, as well as and socio-economic factors should be adopted (Iacovou, Stylianidis, Sarris and Agapiou, 2009).

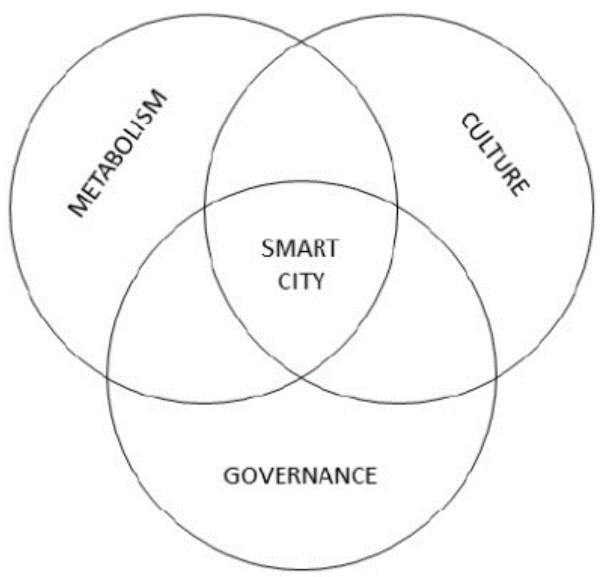

Figure 2. Proposed Smart City framework (Allam and Newman 2018)

Overall, we observe that although significant technological advances have taken place in the area of standalone applications to protect and enhance cultural heritage, and despite the fact that the relative number of academic publications has increased, still in practice the integration of cultural heritage management and promotion within a holistic and multifaceted smart city framework is at a nascent stage.

\section{RESEARCH DESIGN}

The objectives of the present research are to i. update and expand the previously identified strategic relationships between urban smartness and cultural heritage (Angelidou et al. 2017) and to ii. identify the gaps that need to be filled in terms of smart city applications for cultural heritage. 
Smart cities, being complex constructs, can be better understood though observation (Mora et al. 2019). To this end, our research design is based on the investigation of the ways in which cultural heritage management and promotion have been incorporated in smart city initiatives up to date.

The smart city cases that were selected for the purposes of this research were selected on the basis of the following criteria: i) the case of the smart city should be internationally acknowledged for excellence, in order to provide good quality material; ii) there should be enough available published information to perform the analysis; and iii) there should exist a cultural heritage component or a least a broader priority to cultural matters in the smart city strategy. In compliance with the above criteria, the selected smart city initiatives are the following:

- Tarragona smart city, Spain (Fundación Tarragona Smart Region 2018)

- Budapest, Hungary (City of Budapest 2017).

- Karlsruhe, Germany (Karlsruhe City 2019).

For every case we collected information that has been published during the past three years regarding: the overarching structure of the initiative, the positioning of cultural heritage within those smart city strategies and the inclusion of cultural heritage related smart city applications. Our core research findings were inserted in a simplified version of the Digital Strategy Canvas (cogapp 2019), edited by the authors, which includes:

- Strategic context, which refers to the heritage-related strategic priorities of the organisation implementing the smart city initiative.

- Management and Governance, which refer to the organisations responsible for the management of those services, as well as related processes.

- Services, which refer to the offered heritage-related smart city services offered in each city.

Like the previous study, a 'cross-case analysis' was performed (Yin 2003, Eisenhardt 1989). For each case of a smart city, information was collected individually and then systematically compared across the smart city cases per each category of collected information. The results were used to identify emerging trends and build new theoretical constructs about the positioning of cultural heritage within smart city initiatives, as well as the possible gaps that call for future action and research.

\section{RESEARCH RESULTS}

In this section we describe briefly the three selected case studies: the smart city strategies of Tarragona, Budapest and Karlsruhe. For each case we first provide a brief description of the strategy's rationale and approach, and afterwards we describe the role of cultural heritage in each smart city strategy, followed by the Digital Strategy Canvas for each case.

\subsection{Tarragona}

The journey of the city of Tarragona towards intelligence commenced with the hosting of the 2017 Mediterranean Games. This major event kickstarted the development of 'smart' infrastructures combined with cultural changes in the city, which is now making a concentrated effort to sustain, expand and improve this legacy. The Mediterranean climate, culture and traditions of Tarragona are the cornerstone of the
Smart Tarragona initiative. Acknowledging the need for flexibility and ongoing improvement, the strategy is driven by the following strategic objectives (Fundación Tarragona Smart Region 2018): i) economic recovery, creation of new jobs and innovative productive activities; ii) internationalization and development of a global brand for the city; iii) promotion of citizen participation and cultural change; and iv) incorporation of knowledge and technology in decision making and city management. The smart city strategy unfolds across five areas: efficient water management; sustainable urban mobility; healthy lifestyles; heritage and cultural tourism; and energy efficiency.

Heritage and cultural tourism, more particularly, dubbed as 'Smart Heritage', aim to bring out the 2,500-year history and heritage of the city (also acknowledged by UNESCO) to the forefront and promote it as a touristic attraction of the city. Sustainable tourism is linked to historic heritage through gastronomy, cultural events, maritime traditions and related commercial activities. To this end, digital and social technologies that enhance citizens' and visitors' experience of historical places and make known the customs of Mediterranean life are being developed. Finally, all smart cityrelated projects and initiatives are required to respect the heritage of the city (Fundación Tarragona Smart Region 2019).

Specific initiatives in the culture and heritage domain include (Figures 3-6):

- Real-time information about cultural events, sites and related leisure and hospitality activities.

- Twinning with other cities with similar developmental priorities, and joint organisation of activities and cultural events.

- Experimentation with new sustainability concepts in touristic areas.

- Augmented Reality (AR) and Virtual Reality (VR) applications to recreate images of the past in historical sites.
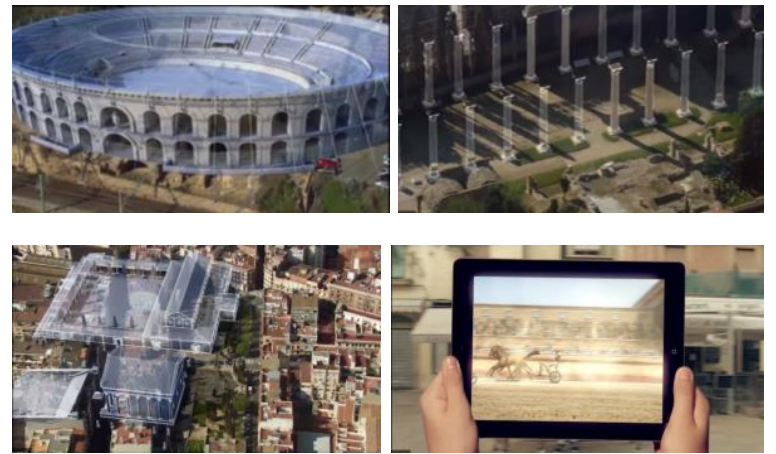

Figures 3-6. AR and VR applications for cultural heritage in Smart Tarragona (Fundació Tarragona Smart 2019).

Digital Strategy Canvas for Tarragona

\section{Strategic context}

- To use the smart city to promote the Mediterranean climate, culture and traditions.

- Five areas: water management; mobility; lifestyles; tourism; energy efficiency.

Management and Governance 
Private sector; academic institutions; utility company; two municipalities.

\section{Services}

- Information: real-time information about leisure and hospitality activities.

- Collaboration: twinnining with other cities.

- Physical pilots: new sustainability concepts in touristic areas.

- AR and VR applications: enhancement of visitor experience in historical sites.

Figure 7. Digital Strategy Canvas for Tarragona (authors elaboration)

\subsection{Budapest}

The smart city vision of Budapest was released in 2017. It is driven by the aims to use advanced technology to capitalise on the city's knowledge and intellectual capital; to take advantage of the city's unique geographic position; and to promote liveability, sustainability and equal opportunities in the city (Smart City Brand 2018). It is seen as an approach of continuous adaptation in the face of rising challenges and opportunities (City of Budapest 2017).

The smart city is seen as a cross-cutting theme providing the horizontal innovation tools and measures that are needed to promote the thematic urban development programmes of the Budapest 2030 Integrated Urban Development Strategy. For example, smart city applications are expected to support the city's programme for port development; the Danube riverside development programme; the city's economic development programme, the city's climate strategy. Importantly for the present research, smart city applications are expected to support the Historic Urban Fabric Renewal programme of the city, as well (City of Budapest 2017).

Cultural heritage, in particular, is identified as the mix of historic values, traditions and identity driving urban renewal in historic areas and other areas of cultural importance. Danube, in this regard, is one of the key determinants of the image of the city's cultural landscape; the riverbanks will host recreational activities, as well as cultural and entertainment spots. The smart city strategy also includes projects to improve sustainable navigation from and to, as well as energy efficiency in places of cultural importance (Smart City Brand 2018). Overall, a more developmental approach is adopted, putting forward smart city initiatives related with the natural and built environment, as well as the city's infrastructure, contributing to the city's integrated long-term urban development strategy.

Specific initiatives in the culture and heritage domain include (Smart City Brand 2018):

- Mapping and optimisation of urban resources (e.g. green and open spaces) and their networks.

- Use of innovative technologies and support Research, Development and Innovation (R\&D\&I) in key sectors.

- Promotion of the production and usage of renewable energy for sewage treatment, heating and other applications, including at sites of cultural importance.

\section{Digital Strategy Canvas for Budapest}

- To use the smart city to promote liveability, sustainability and equal opportunities, contributing to the city's integrated long-term urban development strategy.

- A developmental approach targeting natural and built environment and infrastructure is adopted.

\section{Management and Governance}

Municipality; Private sector; utility companies

\section{Services}

Information and optimisation: mapping and optimisation of urban resources and their networks.

- Research and Development: innovative technologies for R\&D\&I) in key sectors, including cultural heritage preservation and promotion.

Renewable energy in sites of cultural importance.

Figure 8. Digital Strategy Canvas for Budapest (authors' elaboration).

\subsection{Karlsruhe}

Kalsruhe was nominated the award of the European Capital of Smart Tourism in the category "Cultural Heritage and Creativity' for 2020, with five best practices making it to the Compendium of Best Practices of the 2019 European Capital of Smart Tourism competition. In the cultural heritage sector, the city of Karlsruhe is offering its visitors smart city applications that allow them to acquire a richer and often immersive experience of history and significant sights (European Capital of Smart Tourism 2019).

Specific initiatives in the culture and heritage domain include:

- The Stadtgeist application brings images, stories and other content of the past from the city archives to the present. These can be simply viewed through a smartphone camera, as featured in Figures 9 and 10 (bluehands GmbH \& Communication KG 2020).

- The 'Karlsruhe VR' app provides users with $360^{\circ}$ views of important buildings and landmarks in Karlsruhe, as featured in Figures 11 and 12 (Karlsruhe Tourismus $\mathrm{GmbH} 2020$ ).

- The 'Culture in Karlsruhe' initiative, a concentrated marketing effort that brings together 30 of the city's most important cultural institutions, promoting cultural assets, culture-related events and knowledge exchange (European Capital of Smart Tourism 2019).
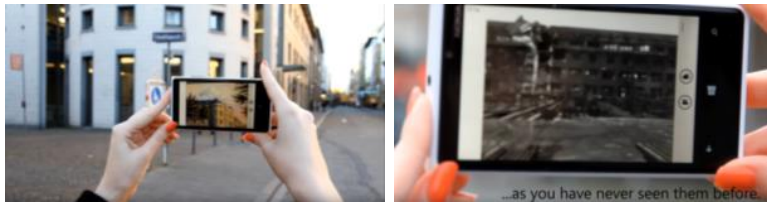

Figures 9 and 10. Instances from Karsruher's Stadtgeist application (bluehands GmbH \& Communication KG 2020).
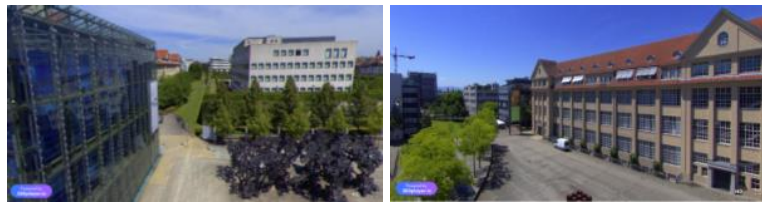

Strategic context 
Figures 11 and 12. Instances from the 'Karlsruhe VR' app (Karlsruhe Tourismus GmbH 2020).

Digital Strategy Canvas for Karlsruhe
Strategic context
- To promote smart cultural heritage as a tourism
development component.
- To use dedicated, as well as other informative app,
combined with offline initiatives.
Management and Governance
Municipality; Private sector; utility companies
Services
- AR and VR applications: enhancement of visitor
experience in historical sites.
- Stakeholder ecosystem development: establishment of
collaboration channels and knowledge exchange
networks across cultural heritage stakeholders.

Figure 13. Digital Strategy Canvas for Budapest (authors' elaboration).

\section{ANALYSIS OF FINDINGS}

The first and overarching observation is that Tarragona, Budapest and Karlsruhe all undeniably have a rich history and a culture-rich physical environment, augmented by important tangible and intangible cultural heritage. They all host important historical buildings, monuments and settings, which play a central role in their approach to the smart city. These advanced in terms of cultural heritage in the smart city contextcities use smart city applications for a variety of aims. More particularly, these aims include: (i) to preserve and protect cultural heritage; (ii) to enhance the cultural experience through representations of the past and storytelling; and (iii) to promote knowledge exchange and the development of stakeholder ecosystems around cultural heritage. Thus, in this first interpretation, a rich cultural heritage is the key ingredient and precondition of smart city development. This is a commonality of all the investigated cities.

Consequently, the second observation is that these more mature -in terms of cultural heritage management- smart city strategies are also clearly tied to touristic branding and promotion. The smart city brand and smart city applications for cultural heritage are seen as a means to enhance the already powerful touristic profile of the city, which is driven by cultural heritage and historical values. More precisely, smart city applications around cultural heritage are leveraged as a means to enhance tourists' experience of the place; to capture augmented experiences and impressions of the past that the visitors will bring back to their homes and share them with others; and to make easier the navigation of tourists around the city and places of cultural importance.

A new dimension to be noted regards the interplay between the smart city, cultural heritage and sustainable urban development. In Tarragona, smart cultural heritage is a key smart city component. In Budapest smart cultural heritage is a way to promote the renewal of the historic urban fabric in the context of the long term sustainable urban development strategy of the city. In this new approach, cultural heritage, along with other areas of importance for urban development and sustainability, are individually addressed and all contribute to the ultimate vision of local sustainability. By contrast, in Karlsruhe cultural heritage is treated as an developmental priority in itself, which can be supported and augmented by smart city applications, next to other activities.

Another important remark in this regard, is the relationship of cultural heritage with the smart city. More specifically, this aspect refers to whether cultural heritage is seen as an asset of the smart city, with the smart city strategy incorporating digital applications in this domain, as are the cases of Tarragona and Budapest, or smart city applications are used as part of the cultural strategy of the city, as is the case with Karlsruhe. Overall, we see that despite the clearer connection of cultural heritage with sustainable and touristic development, its positioning in the architecture of the smart city and/or urban development framework varies. This is depicted in Figure 14, where we can clearly see these different architectures of cultural heritage within the urban intelligence framework.

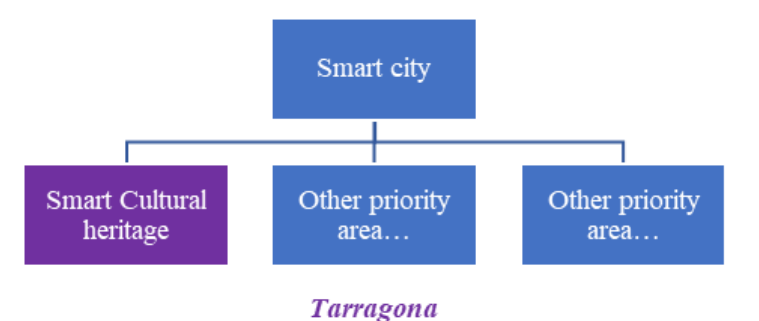

Tarragona
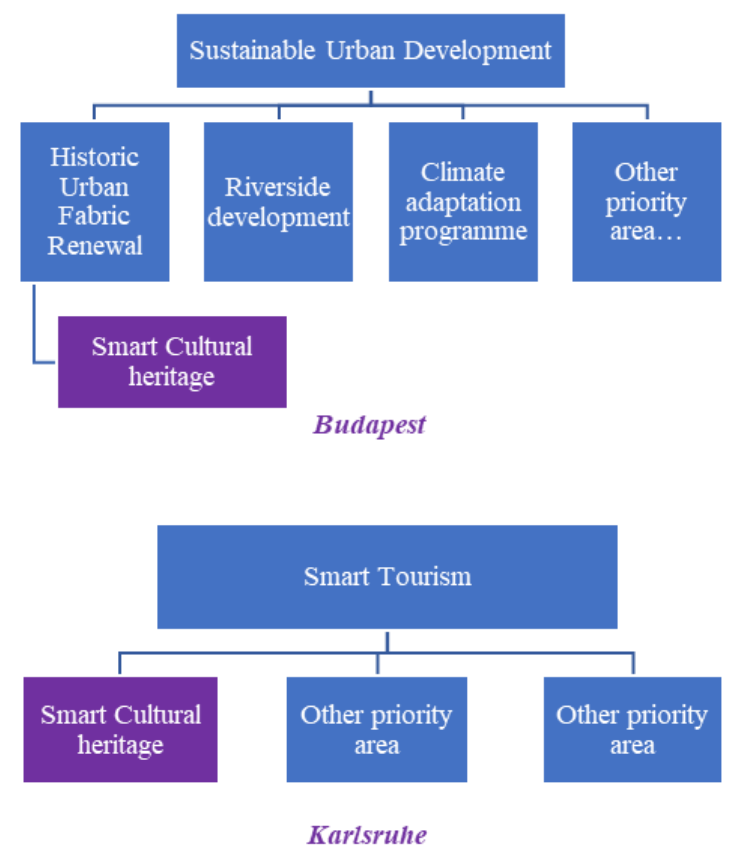

Figure 14. Three different strategy architectures that connect the smart city, cultural heritage and sustainable urban development (authors' elaboration).

Diving into the components of the Digital Strategy Canvas, the first observation is that in terms of strategic context, all three cities have a strong 'social' component and a particular concern for liveability and holistic sustainability (social, economic, environmental, cultural). Regarding management and governance, we observe that multi-stakeholder 
collaboration schemes have come to the interplay. The cities pursuing heritage-related smart city goals smartly partner with the private sector, academic institutions, utility companies, as well as neighbouring municipalities, with the purpose to join forces and expand their competencies. It is characteristic, for example, that many of the culture-related smart city applications in those cities have been developed by private companies but are offered by the cities themselves. Finally, in terms of offered services we identify a broad variety of types, which refer from providing synchronous and asynchronous information, enhancement of visitor experience in historical sites using $\mathrm{AR}$ and $\mathrm{VR}, \mathrm{R} \& \mathrm{D} \&$ for cultural heritage preservation and promotion, and establishment of collaboration channels across cultural heritage stakeholders.

\section{CONCLUSIONS}

In this paper we investigated the progress of the past three yeast regarding the ways in which cultural heritage can be incorporated in smart city strategies. To this end, we analysed individually and comparatively the smart city strategies of three large European cities (Tarragona, Budapest and Karlsruhe), focusing on the structure of the initiative, the interplay of the smart city, cultural heritage and long term urban development goals, and the most common objectives and technologies of heritage-related smart city applications. All three cities share common features: they host important cultural heritage by default; they give specific priority to touristic promotion; their overall approach has an enhanced 'social' component, associated with liveability and sustainable development; and they employ 'smart' multi-stakeholder collaboration schemes to reach their goals. On the other hand, each city chooses to follow a different path towards heritagerelated intelligence, leading also to a variety of technologies and applications being used.

Our overarching conclusion is that opposed to the underlying diversification of the positioning of cultural heritage in smart city strategies, identified three years ago by Angelidou et al. (2017), there is now a clear trend towards more mature and integrated smart city approaches which tie closely cultural heritage both with the history of a city and its strategic goal to promote tourism. From this viewpoint, it could be argued that we are in front of a new generation of smart city initiatives in which cultural heritage is of increasing importance. In this new generation, cultural heritage is a key pillar of social and cultural values, liveability and sustainable urban development. Urban development and alterations in expansion plans is usually based on the analysis of spatial indicators and how they induce the future development in a specific area (Stylianidis, Karanikolas and Kaimaris 2012).

Yet, despite the fact that heritage-related smart city applications and services have well made their way into some smart city agendas, it is not yet clear which types, functionalities and technologies will prevail. Still, smart city applications in this domain are limited in number and scope and employing diverging technologies. The multi-stakeholder environment in which they operate, and particularly the leveraging of the capabilities of the academic/research and private sector in the co-design of those applications, is a key success factor, given that these actors bring in enabling knowledge, competencies and technologies that could not be otherwise accessed by the cities themselves.
In general lines some smart cities have made progress in incorporating the cultural heritage component within their smart city approaches and their use of smart city tools, as well as their long-term vision for innovation and sustainability in the urban context. The definition of a framework of principles for the management of regions of archaeo-cultural value, which are destined to sustain modern development is also very important (Iacovou, Stylianidis, Sarris and Agapiou 2009). Still, however, there is a lot of progress to be made, both in applied and in theoretical terms. In research/theoretical terms, it is necessary to capture and categorise socio-technical developments with regards to cultural heritage in smart city environments, and specifically the context, objectives, approaches, results and impacts of related initiatives. This could be particularly facilitated by means of case study research, given that theoretical knowledge is still limited. On the applied research side, it is important for municipal administrations and heritage-related foundations and organisations to explore the needs of their citizens and visitors in the cultural heritage domain in more depth. Moreover, it is important that they experiment with new operational and business models, both at institutional and ecosystem level. Such models will enable them to upscale their efforts and generate more attractive and sustainable solutions, ultimately enabling profound changes in how cultural heritage is managed and perceived by policy makers, municipal employees, citizens and visitors.

\section{ACKNOWLEDGEMENTS}

This research is co-financed by Greece and the European Union (European Social Fund- ESF) through the Operational Programme «Human Resources Development, Education and Lifelong Learning》 in the context of the project "Reinforcement of Postdoctoral Researchers - 2nd Cycle" (MIS-5033021), implemented by the State Scholarships Foundation (IKY).
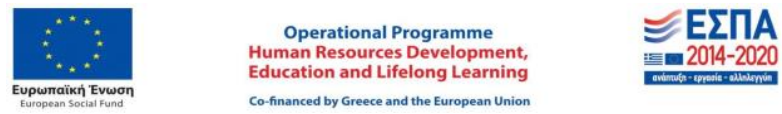

\section{REFERENCES}

Allam, Z., and Newman, P., 2018. Redefining the smart city: Culture, metabolism and governance. Smart Cities 1 (1), 4-25. https://doi.org/10.3390/smartcities1010002

Angelidou, M., Karachaliou, E., Angelidou, T. and Stylianidis, E. 2017. Cultural Heritage in Smart City Environments. 26th International CIPA Symposium 2017, 28 August-01 September 2017, Ottawa, Canada. International Archives of the Photogrammetry, Remote Sensing \& Spatial Information Sciences, XLII-2/W5, 27-32. https://doi.org/10.5194/isprsarchives-XLII-2-W5-27-2017

Angelidou, M., 2017. The Role of Smart City Characteristics in the Plans of Fifteen Cities. Journal of Urban Technology 24 (4), 3-28. http://dx.doi.org/10.1080/10630732.2017.1348880

Angelidou, M. and Mora, L., 2019. Exploring the relationship between smart cities and spatial planning: star cases and typologies. In Smart Cities in the Post-algorithmic Era, 217234. Edward Elgar Publishing. 
bluehands GmbH \& Communication KG, 2020. Stadtgeist Karlsruhe. http://www.stadtgeist-karlsruhe.de/ (10 December 2019).

City of Budapest, 2017. Budapest Urban Development Plans; Smart Budapest. https://budapest.hu/sites/english/Lapok/2017/budapest-urbandevelopment-plans.aspx (11 December 2019).

Cogapp, 2019. The Digital Strategy Canvas. https://www.cogapp.com/digital-strategy-canvas

December 2019)

Cowley, R., Joss, S. and Dayot, Y., 2018. The Smart City and its Publics: Insights from Across six UK Cities. Urban Research \& Practice 11 (1), 53-77. https://doi.org/10.1080/17535069.2017.1293150.

De Falco, S., Angelidou, M. and Addie, J.-P., 2018. From the Smart City to the Smart Metropolis ? Building Resilience in the Urban Periphery. European Urban and Regional Studies 26(2), 205-223. https://doi.org/10.1177/0969776418783813.

Dixon, T., 2018. Smart and Sustainable?: The Future of 'Future Cities' In Sustainable Futures in the Built Environment to 2050: A Foresight Approach to Construction and Development, 94-116. Oxford, UK: John Wiley \& Sons Ltd.

EIP-SCC, 2016. European Innovation Partnership on Smart Cities and Communities. https://eusmartcities.eu/conversation/interview-pieter-van-der-ploeg (10 December 2019).

Eisenhardt, K. M., 1989. Building Theories from Case Study Research. The Academy of Management Review 14 (4), 532550. https://www.jstor.org/stable/258557.

Euractiv, 2017. How Many Smart Cities are there in Europe? Accessed $\quad 30 \quad$ May 2017. https://www.euractiv.com/section/digital/infographic/howmany-smart-cities-are-there-in-europe/ (6 October 2018).

European Capital of Smart Tourism, 2019. Compendium of Best Practices '2019 European Capital of Smart Tourism competition'. https://smarttourismcapital.eu/best-practices/ (18 December 2019).

Fundació Tarragona Smart, 2019. Realitat Virtual pel foment de Tarragona Smart Heritage. https://youtu.be/8T9MQow9DY (10 December 2019).

Fundación Tarragona Smart Region, 2018. https://www.tarragonasmart.cat/mediterranean-city/ January 2020).

Fundación Tarragona Smart Region, 2019. Tarragona Smart Mediterranean City; Smart Heritage. https://www.tarragonasmart.cat/mediterranean-city/projectesestrategics/smart-heritage/ (10 December 2019).

Iacovou, M., Stylianidis, E., Sarris, A., and Agapiou, A., 2009. A long-term response to the need to make modern development and the preservation of the archaeo-cultural record mutually compatible operations. The GIS contribution. 22nd CIPA Symposium, October 11-15, Kyoto, Japan.
Karlsruhe City, 2019. Karlsruhe Smarter City. https://www.karlsruhe.de/int/i2/standort/smart.en (4 January 2020).

Karlsruhe Tourismus GmbH, 2020. Karlsruhe VR. https://www.karlsruhe-tourismus.de/karlsruhe-vr (4 January 2020).

Koukopoulos, Z., 2019. Design and evaluation methodologies of intelligent digital environments for culture and society (Doctoral Thesis). University of Patras. https://www.didaktorika.gr/eadd/handle/10442/46315?locale =en (5 January 2020).

Koukopoulos, Z., Koukopoulos, D. and Jung, J. J., 2018. Realtime crowd management for cultural heritage events: A case study on carnival parades. Journal of Ambient Intelligence and $\begin{array}{llll}\text { Smart } & \text { Environments } & 10 & \text { (3):275-287. }\end{array}$ https://doi.org/10.3233/ais-180485

Kourtit, K.. 2019. Cultural heritage, smart cities and digital data analytics. Eastern Journal of European Studies 10 (1), 151-159.

https://EconPapers.repec.org/RePEc:jes:journl:y:2019:v:10:p: 151-159

Monteiro, F., Mar, A., Amorim, M. Entrecanales, R. R., Henon, A., San José Alonso, S., Gandini, A., Pérez, R., Abián, M. A., and Garcia, J. C., 2018. Smart Heritage ManagementThe SHCity Project Approach. 2018 International Conference on Intelligent Systems (IS).

Mora, L., Deakin, M., Reid, A., and Angelidou, M., 2019. How to Overcome the Dichotomous Nature of Smart City Research: Proposed Methodology and Results of a Pilot Study. Journal $\begin{array}{lllll}\text { of Urban Technology } 26 & \text { (2), 89-128. }\end{array}$ https://doi.org/10.1080/10630732.2018.1525265

Mora, L., Reid, A., and Angelidou, M., 2019. The current status of smart city research: exposing the division. In Smart Cities in the Post-algorithmic Era, 17-35. Edward Elgar Publishing.

Municpality of Heraklion, 2019. Heraklion Smart City. Accessed $26 \quad$ January 2019. https://smartcity.heraklion.gr/en/home/ (4 December 2019).

Piccialli, F. and Chianese, A., 2018. Editorial for FGCS special issue: the internet of cultural things: towards a smart cultural heritage. 81, 514-515.

Smart City Brand, 2018. Smart City Budapest: Charisma, historic values and future. http://smartcitybrand.com/smartcity/charisma-historic-values-and-future (4 December 2019).

Stadt Wien, 2019. Smart City Wien - Die Stadt fürs Leben. https://smartcity.wien.gv.at/site/en/ (23 January 2019).

Stokholms Stad, 2017. Strategy for a smart and connected city. https://international.stockholm.se/governance/smart-andconnected-city/strategy-for-a-smart-and-connected-city/ January 2019).

Stylianidis, E., Karanikolas, N. and Kaimaris, D., 2011. A GIS for urban sustainability indicators in spatial planning. International Journal of Sustainable Development and Planning 7(1), 1-13. 
Trinchini, L. and Spyriadis, T., 2019. Towards Smart Creative Tourism. In Smart Tourism as a Driver for Culture and Sustainability, 451-465. Springer.

UNESCO, 2019. World Heritage Cities Programme. https://whc.unesco.org/en/cities/ (4 January 2020).

UNESCO World Heritage Centre, 2019. The UNESCO Recommendation on the Historic Urban Landscape. France. https://whc.unesco.org/en/hul/ (7 January 2020).

Valentini, F., Calcaterra, A., Antonaroli, S. and Talamo, M., 2018. Smart Portable Devices Suitable for Cultural Heritage: A Review. Sensors $18 \quad$ (8), 2434. https://doi.org/10.3390/s18082434

Yin, R., 2003. Case Study Research: Design and Methods. 3rd edition ed. London: SAGE Publications. 